\title{
New Coordination Approach to Minimize the Number of Re-adjusted Relays When Adding DGs in Interconnected Power Systems
}

\author{
Doaa Khalil Ibrahim ${ }^{\dagger}$, Essam EI Din Abo El Zahab* and Saadoun Abd El Aziz Mostafa**
}

\begin{abstract}
The presence of DGs in power system networks tends to negatively affect the protective relays coordination. The proposed method introduces an approach to minimize the numbers of relays that acquire new settings on contrary to their original settings (case without DG), to achieve relays coordination in case of adding DG, since relays coordination with minimum number of relays of readjusted settings represents economical target, especially in networks containing mixture of electromechanical and adaptive digital relays. The scheme decides the possible minimum number of re-adjusted relays and their locations in an optimum manner to achieve proper relays coordination in case of adding DGs. The proposed approach is divided into two successive phases; the first phase is stopped when the first relays coordination solution is achieved. The second phase increases the possibility to keep higher number of relays at their original settings than that obtained in first phase through achieving multi solutions of relays coordination. The proposed approach is implemented and effectively tested on the well-known IEEE-39 bus test system.
\end{abstract}

Keywords: Distributed Generation (DG), Pickup Current Setting (IP), Relays Coordination, TimeDial Setting (TDS).

\section{Introduction}

With the rapid increase in electrical energy demand, utilities are seeking for more power generation capacity. Newer technologies based on renewable energy sources are becoming more acceptable solutions as alternative energy generators. This renewable energy starts to spread electric power over distribution networks in the form of distributed generation (DG) [1]. Adding DG units in distribution networks will have major impacts on these networks' protection systems. These impacts include increasing short circuit levels, loss of protection coordination especially in case of directional overcurrent relays (DOCRs), bidirectionality of protection devices and protection blindness. Losing relays coordination results in unwanted false tripping for some healthy feeders. Furthermore, it may cause long time delay for tripping and isolating faulty feeders, resulting in significant fault currents overstresses on power system equipment and reducing their life time [2].

Various approaches have been proposed and reported in the literature to solve the coordination problem of directional overcurrent relays. These efforts may be categorized in two main categories. The first category is based on topological analysis, including graph theoretic

$\dagger$ Corresponding Author: Electrical Power and Machines Dept., Faculty of Engineering, Cairo University, Egypt.

(doaakhalil73@eng.cu.edu.eg)

* Electrical Power and Machines Dept., Faculty of Engineering, Cairo University, Egypt. (zahab0@eng.cu.edu.eg)

**Arab Contractor Company, Egypt. (saadoun_abdelaziz12@yahoo.com)

Received: January 29, 2016; Accepted: November 8, 2016 and functional dependencies techniques [3-6]. The second category to solve the coordination problem of DOCRs is based on using optimization techniques, by which the coordination problem could be formulated as a linear or nonlinear programming problem. In the linear model, the time dial settings are only optimized while the pickup current settings values are fixed [7]. Many efforts have been exerted to solve the relays coordination problem and get optimum solutions by applying different recent evolutionary algorithms (EAs) such as: Particle Swarm Optimization (PSO), Genetic Algorithm (GA), and Biogeography-Based Optimization (BBO) as introduced in [8-10]. In [8], a modified particle swarm optimization method is proposed to formulate DOCRs coordination problem as a mixed integer nonlinear problem to get optimal relays settings taking into consideration the discrete values for the pickup current settings. A method based on GA was developed to solve mis-coordination problem using continuous or discrete time setting multipliers [9]. Furthermore, some other hybrid techniques have been proposed to reach optimal solution of DOCRs coordination and overcome the drawback of low convergence speed of evolutionary algorithms; however, these algorithms such as hybrid BBO with linear programming (BBO-LP) are more complex for implementation [10].

For the sake of fixing relays settings for meshed distribution systems in both cases of with and without DG addition, it is proposed in [11] to ensure maximization of allowable DG penetration level at each bus based on measuring the rate of change of the maximum DG penetration level with respect to the rate of change of 
coordination time interval which can serve as an effective measure of DG impacts on relays coordination.

Authors believe that there is still much room for developing efficient schemes to solve relays coordination problem in interconnected power systems when adding DGs. Therefore, a coordination scheme is proposed in this paper to overcome the impact of installing DGs on the protection of interconnected power systems. Generally, the proposed method introduces an approach to minimize the numbers of relays that acquire new settings other than their original settings (case without DG), to achieve relays coordination in case of adding DG. The objective function in the proposed approach is the minimization of the total operating time of all primary relays for near end faults. The coordination problem is modeled as a linear programming (LP) problem. In such problems, a linear objective function is subject to linear equality and inequality constraints and can be solved using one of the linear programming techniques, namely: simplex, dual simplex, or two phase simplex technique [12]. To implement the proposed coordination scheme, the two phase simplex technique is applied using the MATLAB optimization function 'linprog', which is considered a simple and efficient tool.

The proposed scheme is tested on the meshed power distribution system of the IEEE 39-bus system equipped with synchronous based DGs, since synchronous based DGs generate higher fault current levels than inverter based DGs resulting in much more impact on the protection systems.

\section{Conventional Coordination Problem}

Achieving proper directional overcurrent relays coordination implies finding $T D S$ and pickup current settings of all the DOCRs in the system so that the sum of operating times of the primary relays for near end faults is minimized while the coordination constraints are satisfied. Accordingly, the objective function is minimizing $T$ as follows [11]:

$$
\text { Minimize } T=\sum_{i=1}^{N} t_{i}
$$

Where, $T$ is the total time of $N$ primary relays for near end faults and $t_{i}$ is the operating time of the primary relay ith for its near end fault. Actually before adding the primary relay operating time to the summation of the objective function of Eq. (1), relay direction either in forward operation (to be added) or reverse operation (to be eliminated) is checked based on the angle between the relay fault current and its polarizing quantity that is not affected by the fault [13].

To ensure relays coordination, the operating time of the backup relay has to be greater than that of the primary relay for the same fault location by a coordination time interval including relay over travel time, breaker operating time, and safety margin for relay error as follows:

$$
t_{j, i}-t_{i} \geq C T I_{j, i}
$$

where $t_{j, i}$ is the operating time of the first back up jth relay for a near end fault at the ith relay, and $C T I_{j, i}$ is the coordination time interval for backup-primary relay pair $(j, i)$. Based on the preceding conducted studies, coordination time interval can be taken between $0.2 \mathrm{~s}$ and $0.5 \mathrm{~s}$.

The boundary conditions of relays settings can be formulated as linear inequality sets by:

$$
\begin{aligned}
& T D S_{i, \min } \leq T D S_{i} \leq T D S_{i, \max } \\
& I_{P_{i, \min }} \leq I_{P_{i}} \leq I_{P_{i, \max }}
\end{aligned}
$$

Where $T D S_{i, \min }, T D S_{i, \max }$ are the minimum and maximum $T D S$ values of relay $R_{i}$ respectively which are assumed to be 0.05 and 1.1 respectively. $I_{P_{i}}$ is the pickup current setting of relay $R_{i}$, and its limits are chosen between 1.25 and 2 times the maximum load current seen by such relay. Relays characteristics are assumed identical and their functions are approximated by [8]:

$$
t_{j, i}=\frac{0.14 T D S_{j}}{\left(\left(\frac{{ }^{I} f_{j, i}}{I_{P_{j}}}\right)^{0.02}-1\right)}
$$

Where $I_{f_{j, i}}$ is the short circuit current passing through the relay $R_{j}$ for a fault at $i$.

For a fixed previously predefined value of $I_{P_{j}}$ within its boundary limits, Eq. (5) can be expressed by TDS coefficient $\left(a_{j, i}\right)$ for relay $R_{j}$ as follows:

$$
t_{j, i}=a_{j, i} \times T D S_{j}
$$

where,

$$
a_{j, i}=\frac{0.14}{\left(\left(\frac{{ }^{I} f_{j, i}}{I_{P_{j}}}\right)^{0.02}-1\right)}
$$

Based on predefined values of $I_{P}$ for all relays, the objective function and the constraints given by Eq. (1), Eq. (2) and Eq. (3) can be expressed by Eq. (8), (9) and (10) respectively:

$$
\begin{aligned}
& \text { Minimize } T=\sum_{i=1}^{N} a_{i, i} \times T D S_{i} \\
& a_{j, i} \times T D S_{j}-a_{i, i} \times T D S_{i} \geq C T I_{j, i} \\
& 0.05 \leq T D S_{i} \leq 1.1
\end{aligned}
$$

As discussed before, this coordination problem is solved in terms of $T D S$, given that $I_{P}$ values of all the relays are predefined, based on the MATLAB optimization function 'linprog' that used with simplex two phase algorithm. 


\section{Proposed Approach Formulation for Readjusting Minimum Number of Relays}

\subsection{Methodology of the first phase of the proposed approach}

The flowchart illustrated in Fig .1 shows detailed steps of the proposed approach. It starts with the solution of conventional coordination problem without DGs addition using previously predefined values of the pickup current for all relays within their limits. The problem of DOCRs coordination could be treated as a LP problem, and then the relays' TDS are calculated to get optimum solution. When a DG is added, the fault currents for all relays are recalculated using a developed MATLAB code and thus applying the original relays settings will result in some violated constraints.

The basic idea of the proposed approach is to restore overall relays coordination in case of adding DG while keeping most of relays at their original settings. To achieve such goal, the proposed approach is divided into two successive phases, where each phase includes number of trials to achieve relays coordination.

The first phase assumes a set $\{I\}$ that includes all violated constraints. It divides the relays into two groups. The first group includes the relays that we could have the ability to re-adjust their original settings, it includes backup-primary relay of each pair of violated constraints in set $\{I\}$. On the other hand, the second group includes the other remaining relays (not included in set $\{I\}$ ) which are kept fixed at their original settings during all trials of the scheme. Meanwhile, trials are carried out to keep most of relays in set $\{I\}$ at their original settings and reduce the number of relays that need to re-adjust their original settings with new settings as possible as we can. Nonetheless, changing settings for one of the relays in set $\{I\}$ may remove an existing violated constraint, but may also generate another violated constraint associated with this relay, and not included in set $\{I\}$. Accordingly, a set $\{K\}$ is constructed, which is defined as the set that contains the violated constraints of set $\{I\}$ in addition to any other constraints associated with each relay in set $\{I\}$, and then tested based on linear programming.

In the first trial, linear programming is carried out on set $\{K\}$ at this step without any change of relays' $I_{P}$. If the relays coordination at this trial is not achieved, the relays' $T D S$ are changed to their original $T D S$ for $N 1$ randomly selected relays in set $\{I\}$ that satisfy Eq. (11) condition:

$$
T D S_{n}^{1}=T D S_{n}^{0} \pm \varepsilon
$$

Where, $n$ is the relay address in set $\{I\}$ that satisfy Eq. (11), $T D S_{n}^{0}$ is the original $T D S$ for relay $n$ that calculated for relays coordination in case without $\mathrm{DG}, T D S_{n}^{1}$ is the $T D S$ of relay $n$ that calculated after completion the first trial, and $\varepsilon$ is the $T D S$ tolerance coefficient which is

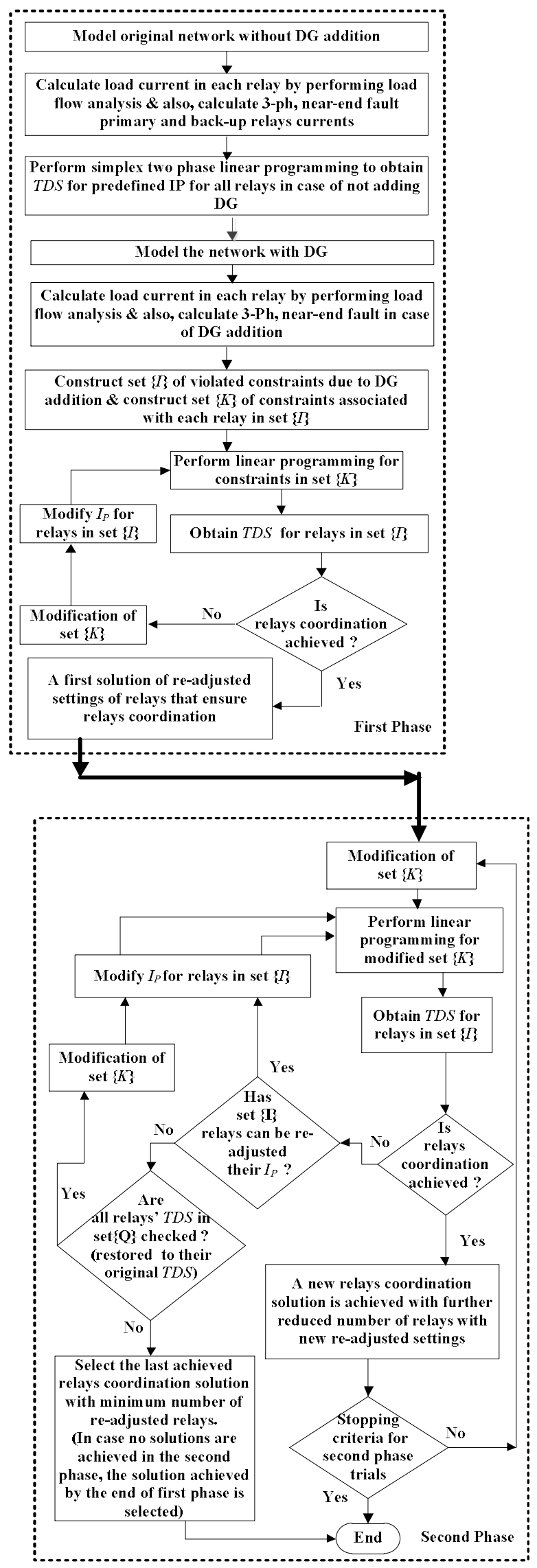

Fig. 1. Flowchart of the proposed approach 
chosen so that $|\varepsilon| \leq 0.01$ in the first phase.

Accordingly, N1 relays are restored their original settings at the starting of the second trial and the above step is repeated while relays' $I_{P}$ are changed for other relays other than $N 1$ relays. Then, linear programming is performed on first modification of set $\{K\}\left(1^{\mathrm{st}} \operatorname{set}\{K\}\right)$, and thus if relays coordination is not achieved in this second trial, the relays' $T D S$ for $N 2$ selected relays in set $\{I\}$ that satisfy the condition of Eq. (12) will be changed to their original $T D S$.

$$
T D S_{n}^{2}=T D S_{n}^{0} \pm \varepsilon
$$

Where, $T D S_{n}^{2}$ is $T D S$ for relay $n$ in set $\{I\}$ that calculated at the completion of the second trial. Consequently, $N 2$ relays are restored their original settings at the starting of the third trial and the above step is repeated while relays' $I_{P}$ are changed for the other relays other than N2 relays, then linear programming is carried out on this $2^{\text {nd }}$ set $\{K\}$.

If relays coordination is achieved in the third trial, and $N 3$ relays in set $\{I\}$ are kept at their original settings by the completion of this trial, it will be verified that relays of original settings have been increased due to the $N 3$ relays those gained in set $\{I\}$ through the three trials where $N 1 \in N 2 \in N 3$. Finally, the first phase is stopped when the first solution for relays coordination is achieved.

\subsection{Methodology of the second phase of the proposed approach}

The second phase of the proposed scheme is an extension to the first phase except that $T D S$ tolerance coefficient value will be greater than the zero value $(\varepsilon \geq 0)$. The objective of the second phase is achieving other solutions for relays coordination based on adding extra relays of original settings to those obtained based on first phase.

Suppose that, the trial step $m+1$ is the trial step at the end of first phase at which first solution of relays coordination occurs, and thus set $\{I\}$ at this step includes subset $\{Q\}$ which have only relays of pickup currents identical to those of original settings. The second phase starts with trial step $\mathrm{m}+2$ based on restoring $T D S$ for chosen relays in subset $\{\mathrm{Q}\}$ to their corresponding original $T D S$, and then the set $\{K\}$ is modified. Consequently, and upon changing relays' $\mathrm{I}_{\mathrm{P}}$, a new set of relays' $T D S$ are obtained again by applying linear programming.

In case of achieving relays coordination at this trial, it is considered a second solution for relays coordination. Repeating the above steps, third, fourth and more solutions for achieving relays coordination could be obtained with further increased number of relays of original settings as the number of trials increases.

On the other hand, in case of not achieving relays coordination at the trial step $\mathrm{m}+2$, the second phase could be restarted again but based on a lower number of selected relays in set $\{Q\}$. Finally, if there is no other solution for relays coordination, the trials are stopped and the relays have kept their original settings are those obtained by the end of the first phase.

Generally, the second phase trials will be stopped when no other solutions are found for relay coordination, or when more optimum solution for relays coordination is achieved with a total operating time of all primary relays for near end faults less than the other generated solutions and first phase solution.

\section{Analysis and Results}

The tested case study in this paper is the 39-bus IEEE system as shown in Fig. 2. It has 345, 230 and $22 \mathrm{kV}$ buses, with 34 lines, 10 generators, 12 transformers and 84 directional overcurrent relays.

\subsection{Optimal conventional relays coordination results for the system without DG}

Continuous $T D S \&$ discrete $I_{P}$ values are allowed in this study, a fixed $I_{P}$ value corresponding to 1.25 times maximum load current is firstly chosen when, the actual load current in the forward direction of relay operation. Otherwise, $I_{P}$ value of $150 \%(1.5 \mathrm{~A})$ is assigned to relays when the actual load current in their reverse direction of operation as assumed in [14]. The values of Ips plug settings values as percentage of the secondary current tap for all relays are shown in Table 1. As clearly shown in the table, all the 84 relays have discrete values of Ips $(50 \%$, $75 \%, 100 \%, 125 \%, 150 \%, 175 \%$, or $200 \%$ ), except only one relay which is R3, it has Ip of $60 \%$. The final achieved results upon adding DG, as will introduced later on, ensure that such relay should be an adaptive relay and have modified settings, so Ip of $60 \%$ is accepted in the case without adding DG for an adaptive one.

Consequently, by applying the steps illustrated in Section 2, relays $T D S$ are generated to achieve optimal relays coordination. The results are given at $C T I=0.2 \mathrm{sec}$.

\subsection{Examining proposed approach for the system with DG}

Then the proposed approach is examined when a synchronous based DG is added at bus 28 , the transient reactance and capacity of the DG are 0.2 pu and 10 MVA respectively. The DG is connected to the network through a transformer of 10 MVA capacity and 0.01 pu reactance. The system is modeled in MATLAB code with all of its detailed parameters. The near-end fault primary and backup relays currents are calculated in the presence of DG.

In fact, the proposed scheme can be applied for DG addition at any location; however, the DG has inserted at 


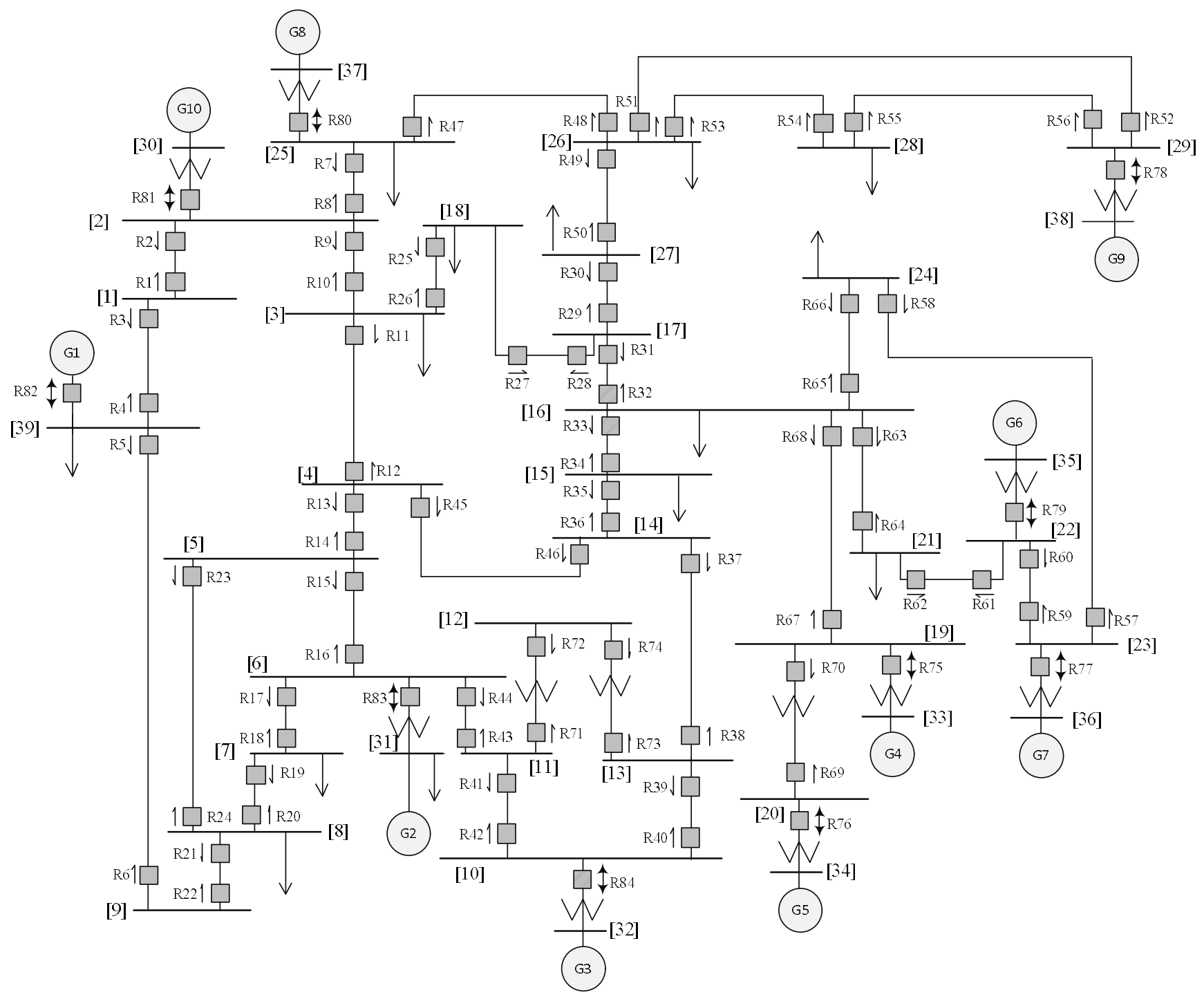

Fig. 2. Tested IEEE-39 bus system

bus 28 to get a complicated case of relays miscoordination. In such case, 47 violation constraints are found which nearly represent one third of the total constraints (140 constraints), also 61 relays out of total 84 relays have been affected by location of DG addition. According to the original calculated relays settings, Table 2 presents CTI of all backup-primary relay pairs in presence of DG. As shown, all 47 violated constraints are presented in shaded bold cells.

Based on the aforementioned stages of the proposed approach, set $\{I\}$ of all violated constraints is constructed (47 constraints of 61 relays), and therefore other relays not included in set $\{I\}$ are kept fixed at their original settings (23 relays). As discussed before, all relays in set $\{I\}$ are of variable settings, and thus set $\{K\}$ of all constraints associated to each relay in set $\{I\}$ is constructed. The constraints before starting trials of the proposed scheme were 140 with no change of $I_{P}$. Table 3 shows the results of re-adjusting minimum number of relays settings in case of adding DG, where:

- Symbol '*' indicates relays' $I_{P}$ of same original setting values as calculated in Table 1 ,

- Cells have bold values, either shaded or not, indicate relays' $T D S$ obtained at the completion of each trial step $\left(1^{\text {st }}, 2^{\text {nd }}, 3^{\text {rd }}, ..\right)$ which are identical to the original $T D S$,

- Cells have shaded values indicate modified values of relays' $T D S$ at the starting of each trial step to be identical to the original $\operatorname{TDS}(N 1, N 2, N 3 \ldots .$.$) ,$

- Cells have normal values (not bold or not shaded) refer to relays' re-adjusted settings that obtained at the completion of each trial step.

- Settings of 23 relays: R1, R21, R22, R38, R53, R63, R67, R68, R69, R70, R71, R73, R74, R75, R76, R77, R78, $\mathrm{R} 79, \mathrm{R} 80, \mathrm{R} 81, \mathrm{R} 82, \mathrm{R} 83$ and $\mathrm{R} 84$ are kept fixed at original settings during all trials, and thus they are not shown in the table. 
Table 1. Ips Plug Settings Values as Percentage of the Secondary Current Tap for Relays in Power System without DG

\begin{tabular}{|c|c|c|c|c|c|c|c|c|c|c|c|}
\hline$I p$ & Value & $I p$ & Value & $I p$ & Value & $I p$ & Value & $I p$ & Value & $I p$ & Value \\
\hline Ipl & 150 & Ip15 & 150 & Ip 29 & 150 & Ip43 & 175 & Ip57 & 175 & Ip71 & 125 \\
\hline Ip2 & 75 & Ip16 & 125 & Ip30 & 50 & Ip44 & 150 & Ip58 & 150 & $I p 72$ & 150 \\
\hline Ip3 & 60 & Ip17 & 100 & Ip31 & 150 & Ip45 & 150 & Ip59 & 150 & $I p 73$ & 125 \\
\hline Ip4 & 150 & Ip18 & 150 & Ip32 & 100 & Ip46 & 150 & Ip60 & 175 & $I p 74$ & 150 \\
\hline Ip5 & 150 & Ip19 & 100 & Ip33 & 175 & Ip47 & 50 & Ip61 & 125 & Ip75 & 125 \\
\hline Ip6 & 150 & Ip20 & 150 & Ip34 & 150 & Ip48 & 150 & Ip62 & 150 & $I p 76$ & 175 \\
\hline Ip7 & 125 & Ip21 & 150 & Ip35 & 150 & Ip49 & 150 & Ip63 & 150 & Ip77 & 125 \\
\hline Ip 8 & 150 & Ip22 & 50 & Ip36 & 150 & Ip50 & 150 & Ip64 & 175 & $I p 78$ & 175 \\
\hline $\operatorname{Ip} 9$ & 200 & Ip23 & 175 & Ip37 & 150 & Ip51 & 150 & Ip65 & 150 & Ip79 & 150 \\
\hline Ip10 & 150 & Ip24 & 150 & Ip38 & 175 & Ip52 & 100 & Ip66 & 50 & Ip 80 & 125 \\
\hline Ip 11 & 75 & Ip25 & 100 & Ip39 & 150 & Ip53 & 150 & Ip67 & 100 & Ip 81 & 150 \\
\hline Ip12 & 150 & IP26 & 150 & Ip 40 & 175 & Ip54 & 100 & Ip68 & 150 & Ip82 & 200 \\
\hline Ip13 & 150 & IP27 & 150 & Ip41 & 150 & Ip55 & 150 & Ip69 & 150 & Ip83 & 125 \\
\hline Ip14 & 100 & Ip28 & 100 & Ip42 & 200 & Ip56 & 175 & $I p 70$ & 100 & Ip84 & 150 \\
\hline
\end{tabular}

* Shaded cells mean actual current is in reverse direction of relay operation.

Table 2. CTI of All Backup-Primary Relay Pairs in Presence of DG at bus 28

\begin{tabular}{|c|c|c|c|c|c|c|c|c|c|}
\hline CTI & $\begin{array}{l}\text { Value } \\
\text { (in sec) }\end{array}$ & $C T I$ & $\begin{array}{c}\text { Value } \\
\text { (in sec) }\end{array}$ & $C T I$ & $\begin{array}{c}\text { Value } \\
\text { (in sec) }\end{array}$ & $C T I$ & $\begin{array}{l}\text { Value } \\
\text { (in sec) }\end{array}$ & $C T I$ & $\begin{array}{c}\text { Value } \\
\text { (in sec) }\end{array}$ \\
\hline$C T I 4,1$ & 0.2 & CTI 54,49 & -0.0177 & CTI 78,56 & 0.3295 & CTI 12,26 & 0.2008 & CTI 40,73 & 28.1141 \\
\hline$C T I 7,2$ & 0.6361 & CTI 52,49 & 0.0876 & CTI 54,51 & 0.6899 & $C T I 82,4$ & 0.2000 & CTI 76,69 & 0.5676 \\
\hline CTI 10,2 & 0.6482 & CTI 47,49 & 0.2336 & CTI 47,51 & 0.8972 & CTI 6,4 & 0.1997 & $C T I 75,70$ & 2.2586 \\
\hline CTI 81,2 & 0.6565 & $C T I 7,9$ & 0.1912 & CTI 50,51 & 0.7187 & CTI 82,5 & 0.2718 & CTI 75,67 & 0.2000 \\
\hline CTI 1,8 & 0.2005 & $C T I 1,9$ & 0.2095 & CTI 55,52 & 0.1573 & $C T I 3,5$ & 0.1991 & CTI 69,67 & 0.2000 \\
\hline CTI 10,8 & 0.1983 & CTI 12,10 & 0.3610 & $C T I 78,52$ & 0.5018 & CTI 25,11 & 0.2788 & CTI 38,46 & 0.4091 \\
\hline CTI 81,8 & 0.2005 & CTI 25,10 & 0.1985 & CTI 49,30 & 0.1769 & $C T I 9,11$ & 0.4385 & CTI 35,46 & 0.4020 \\
\hline CTI 48,7 & 0.1915 & CTI 29,50 & 0.1999 & CTI 32,29 & 0.2970 & CTI 14,12 & 0.2001 & CTI 14,45 & 0.2391 \\
\hline CTI 80,7 & 0.2101 & CTI 52,53 & 0.7327 & CTI 27,29 & 0.3087 & CTI 46,12 & 0.1990 & $C T I 11,45$ & 0.1983 \\
\hline$C T I 8,47$ & 0.1997 & CTI 47,53 & 0.8367 & CTI 26,27 & 0.1998 & CTI 41,40 & 0.1998 & $C T I 2,3$ & 0.1997 \\
\hline$C T I 80,47$ & 0.3153 & CTI 50,53 & 0.6589 & CTI 30,28 & 0.2047 & CTI 84,40 & 0.2005 & CTI 42,43 & 0.1998 \\
\hline CTI 54,48 & 0.1457 & CTI 56,54 & 0.2517 & CTI 32,28 & 0.2039 & CTI 74,39 & 0.2000 & CTI 83,43 & 1.2895 \\
\hline CTI 52,48 & 0.2521 & CTI 53,55 & 0.2521 & CTI 28,25 & 0.1981 & CTI 37,39 & 0.1998 & CTI 72,43 & 0.4075 \\
\hline CTI 50,48 & 0.2174 & CTI 51,56 & 0.1958 & CTI 9,26 & 0.1964 & CTI 84,39 & 0.4840 & CTI 44,41 & 0.1999 \\
\hline CTI 72,41 & 0.1987 & CTI 83,16 & 0.4133 & CTI 11,13 & 0.4629 & CTI 23,21 & 0.3319 & CTI 60,57 & 0.2000 \\
\hline CTI 39,42 & 0.1998 & CTI 35,37 & 0.1996 & CTI 16,14 & 0.1999 & CTI 19,24 & 0.1997 & CTI 77,57 & 0.2530 \\
\hline CTI 84,42 & 0.2677 & CTI 45,37 & 0.2053 & CTI 24,14 & 0.2000 & CTI 22,24 & 0.2833 & CTI 65,58 & 0.1998 \\
\hline CTI 18,44 & 0.1997 & CTI 74,38 & 0.2855 & CTI 5,22 & 0.2000 & $C T I 21,6$ & 0.2000 & CTI 77,59 & 0.2000 \\
\hline CTI 83,44 & 0.2071 & CTI 40,38 & 0.2000 & CTI 13,23 & 0.2969 & CTI 66,63 & 0.5385 & CTI 58,59 & 0.1993 \\
\hline CTI 43,17 & 0.5030 & CTI 33,35 & 0.1990 & CTI 16,23 & 0.5114 & CTI 67,63 & 0.5342 & CTI 64,65 & 0.2010 \\
\hline CTI 15,17 & 0.1996 & CTI 38,36 & 0.2001 & CTI 31,33 & 0.1962 & CTI 31,63 & 0.4370 & CTI 67,65 & 0.6035 \\
\hline CTI 83,17 & 0.7235 & CTI 45,36 & 0.1994 & CTI 66,33 & 0.2903 & CTI 34,63 & 0.5299 & CTI 31,65 & 0.5099 \\
\hline CTI 20,18 & 0.2000 & CTI 30,31 & 0.1928 & CTI 67,33 & 0.2909 & CTI 61,64 & 0.1998 & CTI 34,65 & 0.6021 \\
\hline CTI 83,18 & 1.6627 & CTI 27,31 & 0.2039 & CTI 36,34 & 0.1999 & CTI 62,60 & 0.1990 & CTI 57,66 & 0.1995 \\
\hline$C T I 24,15$ & 0.4112 & CTI 34,32 & 0.1991 & CTI 17,19 & 0.1997 & CTI 79,60 & 0.2003 & CTI 66,68 & 1.2629 \\
\hline$C T I 13,15$ & 0.1997 & CTI 66,32 & 0.2002 & CTI 22,20 & 0.2001 & CTI 59,61 & 0.1999 & CTI 64,68 & 0.8590 \\
\hline CTI 18,16 & 0.4136 & CTI 67,32 & 0.2002 & CTI 23,20 & 0.1994 & CTI 79,61 & 0.3970 & CTI 34,68 & 1.2603 \\
\hline CTI 43,16 & 0.1993 & CTI 46,13 & 0.5022 & CTI 19,21 & 1.6215 & CTI 63,62 & 0.2000 & CTI 31,68 & 1.1670 \\
\hline
\end{tabular}

* Shaded bold cells show the mis-coordinated backup-primary relay pairs in presence of DG.

As the objective of the proposed approach is to keep most of relays at their original settings and fulfill relays coordination in case of adding DG, detailed results for gradually reducing the number of relays that need readjusting their original settings to achieve relays coordination are shown below:

- During the first trial to obtain relays coordination, a set $\{K\}$ of 134 constraints associated with 61 relays in set $\{I\}$ is developed, then linear programming is performed on set $\{K\}$ with no change of $I_{P}$ for all relays, and thus $[\mathrm{TDS}]^{1}$ is obtained at the end of first trial, where $[\mathrm{TDS}]^{1}$ is the $T D S$ for all relays in set $\{I\}$ that calculated at the completion of the first trial. By the end of this trial, it is found that relays coordination is not achieved.

- Consequently, the second trial is initiated by comparing the obtained [TDS $]^{1}$ for 61 relays in set $\{I\}$ and their corresponding original values in $[\mathrm{TDS}]^{0}$. Therefore only 11 relays are selected to change their $T D S$ into their corresponding original values (N1 relays). Cells have shaded values in 'Second Trial column' refer to these relays (e.g. TDS of R19 is changed from 0.3046 to 0.3052 at the start of the second trial). $1^{\text {st }}$ modified $\operatorname{set}\{K\}$ 


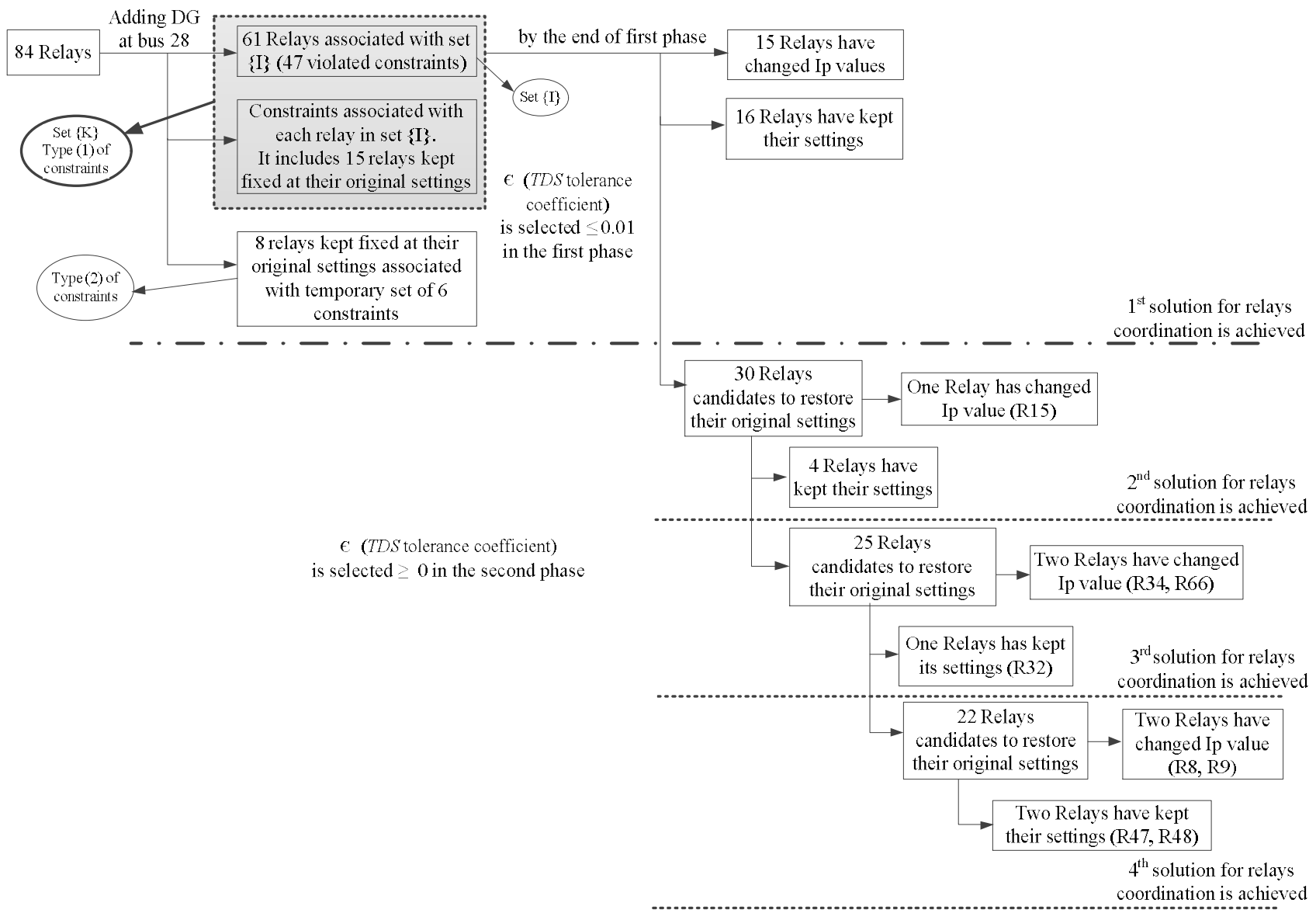

Fig. 3. Summary for the proposed approach results in case of adding DG at bus 28 during the first and second stages

is constructed to have 124 constraints taking into consideration the original settings for both 11 relays in set $\{I\}$ and the 23 relays not included in $\operatorname{set}\{\mathrm{I}\}$. $I_{P}$ for other relays other than the 11 relays in set $\{I\}$ are changed and then linear programming steps are applied on the new $1^{\text {st }}$ set $\{K\}$.

- The third trial is started to achieve relays coordination when comparing the obtained [TDS $]^{2}$ for relays in $\operatorname{set}\{I\}$ and their corresponding original values in $[\mathrm{TDS}]^{0}$, and consequently only 5 relays satisfying the condition of Eq. (12) are selected in addition to 11 relays (those obtained in second trial) to restore their $T D S$ at their corresponding original values in this trial, cells have shaded values in 'Third Trial column' refer to these relays ( $N 2$ relays). $2^{\text {nd }} \operatorname{set}\{K\}$ is constructed to have 118 constraints taking into consideration the original settings for both 16 relays in $\operatorname{set}\{I\}$ and the 23 relays not included in set $\{I\} . I_{P}$ for other relays other than the 16 relays in set $\{I\}$ are changed and then linear programming steps are applied. Based on the achieved results, it is found that relays coordination is achieved for the first time at this third trial keeping 16 of 61 relays in set $\{I\}$ at their original settings. Hence, 39 relays are kept at their original settings as shown in 16 cells that have bold values in 'Third Trial column', in addition to 23 relays not included in set $\{I\}$.

However there is still a possibility to further increase this number of relays with original settings and achieve relays coordination based on the second phase as follows:

- The fourth trial is initiated to achieve a second solution of relays coordination; the above steps are repeated with $\varepsilon \geq 0$. The set $\{Q\}$, which includes relays that can change their $T D S$ to their corresponding original values, is $\{\mathrm{R} 7, \mathrm{R} 8, \mathrm{R} 9, \mathrm{R} 10, \mathrm{R} 12, \mathrm{R} 13, \mathrm{R} 15, \mathrm{R} 23, \mathrm{R} 26, \mathrm{R} 27$, R29, R32, R34, R36, R37, R39, R45, R46, R47, R48, R50, R51, R54, R55, R57, R60, R62, R64, R65, and $\mathrm{R} 66\}$. Four relays in set $\{\mathrm{Q}\}$ are selected and tested in addition to 39 relays. $I_{P}$ is changed for relays to be as listed in 'Fourth Trial column' in Table 3, and then linear programming is performed on $3^{\text {rd }}$ set $\{K\}$ ensured that a second solution of relay coordination is achieved in the fourth trial while keeping 43 relays at their original settings.

- R32 is added in the fifth trial, thus achieving third solution of relays coordination, while addition of R47 and R48 in the sixth trial ensured fourth solution of relays coordination when 46 relays are kept at their original settings (cells have bold values in 'Sixth Trial column'). 
Table 3. Proposed Approach Results of Re-adjusting Minimum Number of Relays Settings in Case of Adding DG

\begin{tabular}{|c|c|c|c|c|c|c|c|c|c|c|c|c|c|c|}
\hline \multirow{2}{*}{$\begin{array}{c}\text { Relay } \\
\text { no. }\end{array}$} & \multicolumn{2}{|c|}{$\begin{array}{c}\text { Original Settings } \\
\text { without DG }\end{array}$} & \multicolumn{2}{|c|}{$\begin{array}{l}\text { First } \\
\text { Trial }\end{array}$} & \multicolumn{2}{|c|}{ Second Trial } & \multicolumn{2}{|c|}{ Third Trial } & \multicolumn{2}{|c|}{ Fourth Trial } & \multicolumn{2}{|c|}{ Fifth Trial } & \multicolumn{2}{|c|}{ Sixth Trial } \\
\hline & $I p$ & TDS & $I p$ & $T D S$ & $I p$ & $T D S$ & $I p$ & $T D S$ & $I p$ & $T D S$ & $I p$ & $T D S$ & $I p$ & $T D S$ \\
\hline R2 & $*$ & 0.3182 & * & 0.3186 & $*$ & 0.3182 & $*$ & 0.3182 & $*$ & 0.3182 & $*$ & 0.3182 & $*$ & 0.3182 \\
\hline R3 & $*$ & 0.2783 & $*$ & 0.2786 & $*$ & 0.2782 & 75 & 0.2481 & 75 & 0.2481 & 75 & 0.2481 & 75 & 0.2481 \\
\hline $\mathrm{R} 4$ & * & 0.6574 & $*$ & 0.6571 & * & 0.6574 & $*$ & 0.6574 & $*$ & 0.6574 & * & 0.6574 & $*$ & 0.6574 \\
\hline R5 & * & 0.5986 & $*$ & 0.5986 & * & 0.5986 & $*$ & 0.5986 & $*$ & 0.5986 & $*$ & 0.5986 & $*$ & 0.5986 \\
\hline R6 & * & 0.3838 & $*$ & 0.3838 & * & 0.3838 & 300 & 0.2811 & 300 & 0.2811 & 300 & 0.2811 & 300 & 0.2811 \\
\hline R7 & * & 0.3371 & $*$ & 0.3403 & * & 0.3318 & $*$ & 0.3162 & $*$ & 0.3402 & $*$ & 0.3402 & $*$ & 0.3198 \\
\hline R8 & * & 0.6888 & $*$ & 0.6864 & * & 0.6459 & $*$ & 0.6205 & * & 0.6205 & $*$ & 0.6205 & 4800 & 0.0748 \\
\hline R9 & * & 0.3704 & $*$ & 0.3714 & $*$ & 0.3603 & $*$ & 0.3401 & * & 0.3713 & $*$ & 0.3713 & 300 & 0.286 \\
\hline R10 & $*$ & 0.6329 & $*$ & 0.6318 & * & 0.6005 & * & 0.5809 & * & 0.5809 & * & 0.5809 & $*$ & 0.4072 \\
\hline R11 & * & 0.4815 & $*$ & 0.4819 & * & 0.4804 & * & 0.4815 & * & 0.4815 & * & 0.4815 & * & 0.4815 \\
\hline R12 & * & 0.6858 & $*$ & 0.6834 & $*$ & 0.6652 & $*$ & 0.6278 & * & 0.6858 & $*$ & 0.6858 & * & 0.6858 \\
\hline R13 & $*$ & 0.5096 & * & 0.6142 & $*$ & 0.6153 & $*$ & 0.4757 & * & 0.5096 & * & 0.5096 & * & 0.5096 \\
\hline R14 & * & 0.4235 & $*$ & 0.4222 & * & 0.4231 & $*$ & 0.4235 & $*$ & 0.4235 & $*$ & 0.4235 & $*$ & 0.4235 \\
\hline R15 & * & 0.3443 & $*$ & 0.4321 & * & 0.4331 & $*$ & 0.3157 & 200 & 0.2793 & 200 & 0.2793 & 200 & 0.2793 \\
\hline R16 & $*$ & 0.2445 & $*$ & 0.2439 & $*$ & 0.2443 & 200 & 0.1602 & 200 & 0.1602 & 200 & 0.1602 & 200 & 0.1602 \\
\hline R17 & $*$ & 0.2303 & $*$ & 0.23 & * & 0.2303 & 150 & 0.1669 & 150 & 0.1669 & 150 & 0.1669 & 150 & 0.1669 \\
\hline R18 & * & 0.319 & $*$ & 0.319 & * & 0.319 & 200 & 0.2585 & 200 & 0.2585 & 200 & 0.2585 & 200 & 0.2585 \\
\hline R19 & * & 0.3052 & $*$ & 0.3046 & * & 0.3052 & $*$ & 0.3052 & $*$ & 0.3052 & $*$ & 0.3052 & $*$ & 0.3052 \\
\hline R20 & $*$ & 0.539 & $*$ & 0.5391 & $*$ & $\begin{array}{l}0.539 \\
\end{array}$ & $*$ & 0.539 & * & $\begin{array}{l}0.539 \\
\end{array}$ & * & 0.539 & $*$ & 0.539 \\
\hline R23 & * & 0.2627 & $*$ & 0.2629 & $*$ & 0.2628 & $*$ & 0.2628 & $*$ & 0.2628 & $*$ & 0.2628 & $*$ & 0.2628 \\
\hline R24 & * & 0.479 & $*$ & 0.4778 & $*$ & 0.4786 & 200 & 0.426 & 200 & 0.426 & 200 & 0.426 & 200 & 0.426 \\
\hline R25 & $*$ & 0.702 & * & 0.7018 & * & 0.6725 & 200 & 0.5324 & 200 & 0.5324 & 200 & 0.5324 & 200 & 0.5324 \\
\hline R26 & $*$ & 0.766 & $*$ & 0.7662 & $*$ & 0.7396 & $*$ & 0.691 & $*$ & 0.766 & $*$ & 0.766 & $*$ & 0.766 \\
\hline R27 & $*$ & 0.6594 & $*$ & 0.6595 & $*$ & 0.6329 & $*$ & 0.5843 & $*$ & 0.6065 & $*$ & 0.6065 & $*$ & 0.6065 \\
\hline R28 & $*$ & 0.5052 & $*$ & 0.5058 & $*$ & 0.488 & 140 & 0.4074 & 140 & 0.4074 & 140 & 0.4074 & 140 & 0.4074 \\
\hline R29 & * & 0.6757 & $*$ & 0.6744 & * & 0.7107 & $*$ & 0.6462 & $*$ & 0.6757 & $*$ & 0.6757 & $*$ & 0.6757 \\
\hline R30 & * & 0.8057 & $*$ & 0.8125 & * & 0.7338 & 100 & 0.6101 & 100 & 0.6101 & 100 & 0.6101 & 100 & 0.6101 \\
\hline R31 & * & 0.6529 & $*$ & 0.6553 & $*$ & 0.5808 & 2400 & 0.1307 & 2400 & 0.1307 & 2400 & 0.1307 & 2400 & 0.1307 \\
\hline R32 & $*$ & 0.5297 & * & 0.5283 & * & 0.5128 & $*$ & 0.488 & $*$ & 0.4915 & $*$ & 0.5297 & $*$ & 0.5297 \\
\hline R33 & * & 0.4242 & $*$ & 0.4245 & 200 & 0.3987 & 200 & 0.3987 & 200 & 0.3987 & 200 & 0.3987 & 200 & 0.3987 \\
\hline R34 & $*$ & 0.5943 & $*$ & 0.5933 & $*$ & 0.5785 & $*$ & 0.5548 & $*$ & 0.5581 & 200 & 0.5357 & 200 & 0.5357 \\
\hline R35 & $*$ & 0.6547 & $*$ & 0.6547 & $*$ & 0.6547 & $*$ & 0.6547 & $*$ & 0.6547 & $*$ & 0.6547 & $*$ & 0.6547 \\
\hline R36 & $*$ & 0.6906 & $*$ & 0.6897 & $*$ & 0.675 & $*$ & 0.6513 & * & 0.6545 & * & 0.6851 & * & 0.6851 \\
\hline R37 & * & 0.6883 & * & 0.6879 & * & 0.688 & $*$ & 0.6811 & * & 0.6811 & * & 0.6811 & $*$ & 0.6811 \\
\hline R39 & * & 0.5983 & $*$ & 0.5979 & $*$ & 0.5983 & $*$ & 0.5909 & $*$ & 0.5909 & * & 0.5909 & * & 0.5909 \\
\hline R40 & $*$ & 0.3427 & $*$ & 0.3426 & $*$ & 0.3427 & $*$ & 0.3427 & $*$ & 0.3427 & $*$ & 0.3427 & $*$ & 0.3427 \\
\hline R41 & * & 0.6532 & $*$ & 0.6532 & * & 0.6532 & 200 & 0.5971 & 200 & 0.5971 & 200 & 0.5971 & 200 & 0.5971 \\
\hline R42 & $*$ & 0.2911 & $*$ & 0.2908 & $*$ & 0.2911 & 240 & 0.2597 & 240 & 0.2597 & 240 & 0.2597 & 240 & 0.2597 \\
\hline R43 & $*$ & 0.2706 & $*$ & 0.2702 & $*$ & 0.2706 & $*$ & 0.2706 & $*$ & 0.2706 & $*$ & 0.2706 & $*$ & 0.2706 \\
\hline R44 & $*$ & 0.7491 & $*$ & 0.7491 & $*$ & 0.7491 & $*$ & 0.7491 & * & 0.7491 & $*$ & 0.7491 & $*$ & 0.7491 \\
\hline R45 & * & 0.6752 & $*$ & 0.6747 & $*$ & 0.6723 & * & 0.6665 & * & 0.6665 & $*$ & 0.6708 & * & 0.6708 \\
\hline R46 & $*$ & 0.3281 & $*$ & 0.3273 & $*$ & 0.3199 & $*$ & 0.3046 & $*$ & 0.3283 & * & 0.3283 & $*$ & 0.3283 \\
\hline R47 & * & 0.5419 & $*$ & 0.5394 & $*$ & 0.5011 & $*$ & 0.4771 & * & 0.4771 & $*$ & 0.4771 & * & 0.5419 \\
\hline R48 & * & 0.5392 & $*$ & 0.5472 & * & 0.5894 & $*$ & 0.5145 & $*$ & 0.5471 & $*$ & 0.5471 & $*$ & 0.5392 \\
\hline R49 & $*$ & 0.3516 & $*$ & 0.3601 & $*$ & 0.3301 & 250 & 0.2305 & 250 & 0.2305 & 250 & 0.2305 & 250 & 0.2305 \\
\hline R50 & $*$ & 0.5685 & $*$ & 0.5671 & $*$ & 0.6035 & $*$ & 0.539 & $*$ & 0.567 & $*$ & 0.567 & $*$ & 0.5602 \\
\hline R51 & * & 0.2888 & $*$ & 0.3077 & * & 0.2951 & $*$ & 0.2904 & * & 0.2904 & * & 0.2904 & * & 0.2904 \\
\hline R52 & * & 0.1544 & $*$ & 0.1721 & $*$ & 0.1599 & * & 0.1544 & * & 0.1544 & $*$ & 0.1544 & * & 0.1544 \\
\hline R54 & $*$ & 0.1564 & * & 0.1908 & $*$ & 0.1772 & $*$ & 0.1688 & $*$ & 0.1688 & $*$ & 0.1688 & $*$ & 0.1688 \\
\hline R55 & $*$ & 0.243 & $*$ & 0.2664 & $*$ & 0.2664 & $*$ & 0.26 & * & $0.26^{\prime \prime}$ & $*$ & 0.26 & $*$ & 0.26 \\
\hline R56 & * & 0.1488 & $*$ & 0.1606 & $*$ & 0.152 & $*$ & 0.1488 & $*$ & 0.1488 & $*$ & 0.1488 & $*$ & 0.1488 \\
\hline R57 & $*$ & 0.2151 & $*$ & 0.2147 & $*$ & 0.2101 & $*$ & 0.2028 & $*$ & 0.2038 & $*$ & 0.2032 & $*$ & 0.2032 \\
\hline R58 & $*$ & 0.3874 & $*$ & 0.3877 & $*$ & 0.3874 & $*$ & 0.3874 & $*$ & 0.3874 & $*$ & 0.3874 & $*$ & 0.3874 \\
\hline R59 & * & 0.3787 & $*$ & 0.3787 & $*$ & 0.3784 & 200 & 0.3449 & 200 & 0.3449 & 200 & 0.3449 & 200 & 0.3449 \\
\hline R60 & * & 0.4289 & $*$ & 0.4283 & $*$ & 0.4213 & $*$ & 0.4101 & $*$ & 0.4117 & $*$ & 0.4108 & $*$ & 0.4108 \\
\hline R61 & * & 0.1346 & $*$ & 0.1346 & * & 0.1346 & * & 0.1346 & $*$ & 0.1346 & * & 0.1346 & * & 0.1346 \\
\hline R62 & * & 0.3315 & $*$ & 0.3315 & * & 0.3272 & * & 0.3204 & * & 0.3213 & $*$ & 0.3207 & * & 0.3207 \\
\hline R64 & $*$ & 0.1573 & $*$ & 0.1572 & $*$ & 0.1571 & $*$ & 0.1571 & $*$ & 0.1571 & $*$ & 0.1571 & $*$ & 0.1571 \\
\hline R65 & $*$ & 0.5114 & $*$ & 0.5118 & $*$ & 0.5115 & $*$ & 0.5115 & $*$ & 0.5115 & * & 0.5115 & $*$ & 0.5115 \\
\hline R66 & $*$ & 0.4016 & $*$ & 0.4006 & $*$ & 0.3907 & $*$ & 0.3746 & $*$ & 0.3768 & 100 & 0.2628 & 100 & 0.2628 \\
\hline \multirow[t]{2}{*}{ R72 } & * & 0.2796 & $*$ & 0.2798 & $*$ & 0.2798 & $*$ & 0.2796 & $*$ & 0.2796 & $*$ & 0.2796 & $*$ & 0.2796 \\
\hline & \multicolumn{2}{|c|}{$\begin{array}{l}\text { Relays } \\
\text { coordination is not } \\
\text { achieved yet }\end{array}$} & & $\begin{array}{l}\text { elays } \\
\text { lination is } \\
\text { hieved yet }\end{array}$ & $\begin{array}{r}\text { coord } \\
\text { ac }\end{array}$ & $\begin{array}{l}\text { elays } \\
\text { ation is not } \\
\text { eved yet }\end{array}$ & $\begin{array}{r}\text { Firs } \\
\text { coor } \\
\text { soluti } \\
\text { Firs }\end{array}$ & $\begin{array}{l}\text { elays } \\
\text { nation } \\
\text { (End of } \\
\text { hase) }\end{array}$ & & $\begin{array}{l}\text { I solution } \\
\text { relays } \\
\text { ination is } \\
\text { ieved }\end{array}$ & $\begin{array}{r}\text { Thir } \\
\text { fo } \\
\text { coor } \\
\text { a }\end{array}$ & $\begin{array}{l}\text { solution } \\
\text { elays } \\
\text { hation is } \\
\text { eved }\end{array}$ & $\begin{array}{r}\text { Fou } \\
\mathrm{f} \\
\text { coo } \\
\mathrm{a}\end{array}$ & $\begin{array}{l}\text { solution } \\
\text { relays } \\
\text { nation is } \\
\text { ieved }\end{array}$ \\
\hline
\end{tabular}


Table 4. Results of Applying Proposed Scheme Based on Assumed value of $\varepsilon$ as in Technique [15] for Re-adjusting Relays Settings in case of adding DG

\begin{tabular}{|c|c|c|c|c|c|c|c|c|}
\hline \multirow{2}{*}{ Relay no. } & \multicolumn{2}{|c|}{ Original Settings without DG } & \multicolumn{2}{|c|}{ First Trial } & \multicolumn{2}{|c|}{ Second Trial } & \multicolumn{2}{|c|}{ Third Trial } \\
\hline & $I p$ & $T D S$ & $I p$ & $T D S$ & $I p$ & $T D S$ & $I p$ & $T D S$ \\
\hline $\mathbf{R 2}$ & $*$ & 0.3182 & $*$ & 0.3186 & $*$ & 0.3186 & $*$ & 0.3133 \\
\hline R3 & $*$ & 0.2783 & $*$ & 0.2786 & $*$ & 0.2786 & 75 & 0.2481 \\
\hline R4 & $*$ & 0.6574 & $*$ & 0.6571 & $*$ & 0.6571 & $*$ & 0.6574 \\
\hline R5 & $*$ & 0.5986 & $*$ & 0.5986 & $*$ & 0.5986 & $*$ & 0.5986 \\
\hline R6 & $*$ & 0.3838 & $*$ & 0.3838 & $*$ & 0.3838 & 300 & 0.2811 \\
\hline $\mathbf{R 7}$ & $*$ & 0.3371 & $*$ & 0.3403 & $*$ & 0.3198 & $*$ & 0.3162 \\
\hline R8 & $*$ & 0.6888 & $*$ & 0.6864 & $*$ & 0.5692 & $*$ & 0.6185 \\
\hline R9 & $*$ & 0.3704 & $*$ & 0.3714 & $*$ & 0.3448 & $*$ & 0.3401 \\
\hline R10 & $*$ & 0.6329 & $*$ & 0.6318 & $*$ & 0.5412 & $*$ & 0.5793 \\
\hline R11 & $*$ & 0.4815 & $*$ & 0.4819 & $*$ & 0.4453 & $*$ & 0.4611 \\
\hline R12 & $*$ & 0.6858 & $*$ & 0.6834 & $*$ & 0.6365 & $*$ & 0.6278 \\
\hline R13 & $*$ & 0.5096 & $*$ & 0.6142 & $*$ & 0.4993 & $*$ & 0.4583 \\
\hline R14 & $*$ & 0.4235 & $*$ & 0.4222 & $*$ & 0.3975 & $*$ & 0.3933 \\
\hline R15 & $*$ & 0.3443 & $*$ & 0.4321 & $*$ & 0.3355 & $*$ & 0.301 \\
\hline R16 & $*$ & 0.2445 & $*$ & 0.2439 & $*$ & 0.2319 & 200 & 0.1506 \\
\hline R17 & $*$ & 0.2303 & $*$ & 0.23 & $*$ & 0.2226 & 150 & 0.1568 \\
\hline R18 & $*$ & 0.319 & $*$ & 0.319 & $*$ & 0.319 & 200 & 0.2585 \\
\hline R19 & $*$ & 0.3052 & $*$ & 0.3046 & $*$ & 0.2926 & $*$ & 0.2823 \\
\hline R20 & $*$ & 0.539 & $*$ & 0.5391 & $*$ & 0.5391 & $*$ & 0.5009 \\
\hline R23 & $*$ & 0.2627 & $*$ & 0.2629 & $*$ & 0.2629 & $*$ & 0.2476 \\
\hline R24 & $*$ & 0.479 & $*$ & 0.4778 & $*$ & 0.4544 & 200 & 0.4005 \\
\hline $\mathbf{R 2 5}$ & $*$ & 0.702 & $*$ & 0.7018 & $*$ & 0.6171 & 200 & 0.5281 \\
\hline R26 & $*$ & 0.766 & $*$ & 0.7662 & $*$ & 0.7023 & $*$ & 0.691 \\
\hline R27 & $*$ & 0.6594 & $*$ & 0.6595 & $*$ & 0.5956 & $*$ & 0.5843 \\
\hline R28 & * & 0.5052 & $*$ & 0.5058 & $*$ & 0.4541 & 140 & 0.4046 \\
\hline R29 & $*$ & 0.6757 & $*$ & 0.6744 & $*$ & 0.6119 & $*$ & 0.6462 \\
\hline R30 & $*$ & 0.8057 & $*$ & 0.8125 & $*$ & 0.7338 & 100 & 0.6066 \\
\hline R31 & $*$ & 0.6529 & $*$ & 0.6553 & $*$ & 0.5808 & 2400 & 0.1307 \\
\hline R32 & $*$ & 0.5297 & $*$ & 0.5283 & $*$ & 0.4525 & $*$ & 0.4853 \\
\hline R33 & $*$ & 0.4242 & $*$ & 0.4245 & 200 & 0.3487 & 200 & 0.3987 \\
\hline R34 & $*$ & 0.5943 & $*$ & 0.5933 & $*$ & 0.5208 & $*$ & 0.5521 \\
\hline R35 & $*$ & 0.6547 & $*$ & 0.6547 & $*$ & 0.6547 & $*$ & 0.6547 \\
\hline R36 & $*$ & 0.6906 & $*$ & 0.6897 & $*$ & 0.6173 & * & 0.6486 \\
\hline R37 & $*$ & 0.6883 & $*$ & 0.6879 & $*$ & 0.6183 & $*$ & 0.6367 \\
\hline R39 & $*$ & 0.5983 & $*$ & 0.5979 & $*$ & 0.5265 & $*$ & 0.5454 \\
\hline R40 & $*$ & 0.3427 & $*$ & 0.3426 & $*$ & 0.3426 & $*$ & 0.3427 \\
\hline R41 & $*$ & 0.6532 & $*$ & 0.6532 & $*$ & 0.6532 & 200 & 0.5971 \\
\hline R42 & $*$ & 0.2911 & $*$ & 0.2908 & $*$ & 0.2492 & 240 & 0.2357 \\
\hline R43 & * & 0.2706 & * & 0.2702 & $*$ & 0.2235 & $*$ & 0.2404 \\
\hline R44 & $*$ & 0.7491 & $*$ & 0.7491 & $*$ & 0.7491 & $*$ & 0.7491 \\
\hline R45 & $*$ & 0.6752 & $*$ & 0.6747 & $*$ & 0.6143 & $*$ & 0.6404 \\
\hline R46 & $*$ & 0.3281 & $*$ & 0.3273 & $*$ & 0.3082 & $*$ & 0.3046 \\
\hline R47 & $*$ & 0.5419 & $*$ & 0.5394 & $*$ & 0.5011 & $*$ & 0.4752 \\
\hline R48 & $*$ & 0.5392 & $*$ & 0.5472 & $*$ & 0.5195 & $*$ & 0.5145 \\
\hline R49 & $*$ & 0.3516 & $*$ & 0.3601 & $*$ & 0.3301 & 250 & 0.2276 \\
\hline R50 & $*$ & 0.5685 & $*$ & 0.5671 & $*$ & 0.5432 & $*$ & 0.539 \\
\hline R51 & $*$ & 0.2888 & $*$ & 0.3077 & $*$ & 0.2951 & * & 0.2866 \\
\hline R52 & $*$ & 0.1544 & $*$ & 0.1721 & $*$ & 0.1599 & $*$ & 0.1516 \\
\hline R54 & $*$ & 0.1564 & $*$ & 0.1908 & $*$ & 0.1772 & $*$ & 0.1681 \\
\hline R55 & $*$ & 0.243 & $*$ & 0.2664 & $*$ & 0.2664 & * & 0.2568 \\
\hline R56 & $*$ & 0.1488 & $*$ & 0.1606 & $*$ & 0.152 & * & 0.1461 \\
\hline R57 & $*$ & 0.2151 & $*$ & 0.2147 & $*$ & 0.1923 & $*$ & 0.202 \\
\hline R58 & * & 0.3874 & * & 0.3877 & $*$ & 0.3877 & $*$ & 0.385 \\
\hline R59 & $*$ & 0.3787 & $*$ & 0.3787 & $*$ & 0.3787 & 200 & 0.3449 \\
\hline R60 & $*$ & 0.4289 & $*$ & 0.4283 & $*$ & 0.394 & $*$ & 0.4089 \\
\hline R61 & $*$ & 0.1346 & $*$ & 0.1346 & $*$ & 0.1346 & * & 0.1346 \\
\hline R62 & $*$ & 0.3315 & $*$ & 0.3315 & $*$ & 0.3105 & $*$ & 0.3196 \\
\hline R64 & $*$ & 0.1573 & $*$ & 0.1572 & $*$ & 0.1572 & $*$ & 0.1566 \\
\hline R65 & $*$ & 0.5114 & $*$ & 0.5118 & $*$ & 0.5118 & * & 0.5091 \\
\hline R66 & $*$ & 0.4016 & $*$ & 0.4006 & $*$ & 0.3516 & * & 0.3728 \\
\hline \multirow[t]{2}{*}{ R72 } & $*$ & 0.2796 & $*$ & $\begin{array}{l}0.2798 \\
\end{array}$ & $*$ & 0.2798 & $*$ & 0.2783 \\
\hline & \multicolumn{2}{|c|}{$\begin{array}{l}\text { Relays coordination is not achieved } \\
\text { yet }\end{array}$} & \multicolumn{2}{|c|}{$\begin{array}{c}\text { Relays coordination is not } \\
\text { achieved yet }\end{array}$} & \multicolumn{2}{|c|}{$\begin{array}{c}\text { Relays coordination is not } \\
\text { achieved yet }\end{array}$} & \multicolumn{2}{|c|}{$\begin{array}{l}\text { Solution for relays } \\
\text { coordination is achieved }\end{array}$} \\
\hline
\end{tabular}


As the total operating time of all primary relays for near end faults $\left(\sum_{\mathrm{i}=1}^{84} a_{i, i} \times T D S_{i}\right)$ equals $74.803 \mathrm{sec}, 75.532 \mathrm{sec}$, $75.728 \mathrm{sec}$, and $74.372 \mathrm{sec}$ by the end of first phase (end of $3^{\text {rd }}$ trial), end of $4^{\text {th }}$ trial, end of $5^{\text {th }}$ trial, and end of $6^{\text {th }}$ trial respectively, the second phase will be stopped at the $6^{\text {th }}$ trial at which relays coordination is achieved with a total operating time of all primary relays for near end faults less than the corresponding values of other trials.

Up to the authors' knowledge, very few published research works have investigated the idea of achieving minimum number of relays that acquire new relays settings in case of adding DG. Reference [15] represents one of such studies where nonlinear / linear optimization models are applied using GAMS. It is worth mentioning that the proposed approach is compared with the published method in [15]. So that, the proposed scheme is applied on IEEE39 bus system but based on $\varepsilon=0$ as in technique [15], for re-adjusting relays settings in case of adding DG. The obtained results are shown in Table 4. It is clear that the first trial is the same as achieved by the proposed scheme when relays are initially assumed to be kept at their original settings. At the starting of the second trial, only four relays R5, R35, R44 and R61 are selected to be added to those keeping their original settings where $\varepsilon=0$. During the second trial, $I_{P}$ is only changed for R33 to be as in our study however relays coordination is not achieved. By the third trial completion, the relays coordination is achieved by changing relays' $I_{P}$ as shown in Table. 4 , and keeping the two relays R4, R40 at their original settings, in addition to R5, R35, R44, R61 and the initially 23 relays.

According to the aforementioned results, those are summarized in Fig. 3; the proposed approach has succeeded in achieving its first solution for relays coordination when keeping 39 relays at their original settings, while in the fourth solution 46 relays are obtained for a more optimum relays coordination solution. On the other hand, when applying the proposed approach but based on $\varepsilon=0$ for re-adjusting relays settings in case of adding DG as in technique [15], it has only kept 29 relays at their original settings to achieve a unique solution for relays coordination.

We can summarize that the proposed method has two merits. The first merit is achieving relays coordination and finding out lower number of relays of new settings compared to the other obtained based on using the proposed method but implemented on $\varepsilon=0$ as in previous techniques, this can be achieved in first phase. The second merit is obtaining further reduced number of relays of new settings, through generating many other solutions of relays coordination

\section{Conclusion}

Relays coordination with minimum number of relays of re-adjusted settings represents economical target, especially in networks containing mixture of electromechanical and adaptive digital relays. The paper introduces a new approach to achieve relays coordination in interconnected power systems utilizing DGs with minimum number of relays of re-adjusted settings. An integrated model, using linear programming based on MATLAB optimization toolbox is introduced to verify the effectiveness of the proposed scheme on IEEE-39 bus test system. The proposed approach calculates re-adjusted settings for minimum number of relays and defines their locations to achieve relays coordination in case of adding DG. Initially, first phase is carried out to decrease the number of relays of readjusted settings and obtaining first relays coordination solution, then the second phase is carried out to gradually decrease this number at sequential stages for obtaining different relays coordination solutions.

When comparing the performance of the proposed approach with other published techniques, the achieved results ensured the effectiveness of the proposed approach. In its first phase and by the completion of 3 trials, relays coordination solution is achieved by keeping 39 relays at their original settings, while implementing our approach but, based on assumptions of other published technique, have only succeeded in keeping 29 relays at their original settings. Besides, the number of relays that kept their original settings is increased to be 46 relays in the second phase through more than one solution for relays coordination.

\section{References}

[1] M. Dewadasa, A. Ghosh, and G. Ledwich, "Protection of distributed generation connected networks with coordination of overcurrent relays," in Proceedings of $37^{\text {th }}$ Annual Conference on IEEE Industrial Electronics Society (IECON), Melbourne, VIC, 2011.

[2] T. Amraee, "Coordination of directional overcurrent relays using seeker algorithm," IEEE Transactions on Power Delivery, vol. 27, pp. 1415-1422, 2012.

[3] M. Mansour, S. Mekhamar, and N.S. EL-Kharabawe," A modified particle swarm optimizer for the coordination of directional overcurrent relay," IEEE Transactions on Power Delivery, vol. 22, pp. 1400-1410, 2007.

[4] D. Birla, R. P., Maheshwari, H. O., Gupta, "Timeovercurrent relay coordination: a review," International Journal Emerging Electrical Power System, vol. 2, 2005.

[5] Jenkins, L., Khincha, H., Shivakumar, S., Dash, P., "An Application of Functional Dependencies to the Topological Analysis of Protection Schemes," IEEE Transactions on Power Delivery, vol. 7, pp. 77-83, 1992.

[6] M. H. Hussain , S. R. A. Rahim, I. Musirin, "Optimal Overcurrent Relay Coordination: A Review," in 
Proceedings of Malaysian Technical Universities Conference on Engineering \& Technology 2012, MUCET 2012 Part 1- Electronic and Electrical Engineering Procedia Engineering, vol. 53, pp. 332336, 2013.

[7] J. Urdaneta, R. Nadira, L. G. Perez, “Optimal coordination of directional overcurrent relays in interconnected power systems," IEEE Transactions on Power Delivery, vol. 3, pp. 903-911, 1988.

[8] H.H. Zeineldin, E.F. El-Saadany, M.M.A. Salama, Optimal coordination of overcurrent relays using a modified particle swarm optimization, Electric Power Systems Research, vol. 76, pp. 988-995, 2006.

[9] F. Razavi, H. A. Abyaneh, M. Al-Dabbagh, R. Mohammadi, H. Torkaman, "A new comprehensive genetic algorithm method for optimal overcurrent relays coordination," Electric Power Systems Research, vol. 78 pp. 713-725, 2008.

[10] Albasri, F. A.; Alroomi, A. R.; Talaq, J. H., "Optimal Coordination of Directional Overcurrent Relays Using Biogeography-Based Optimization Algorithms," IEEE Transactions on Power Delivery, vol. 3, pp.1810-1820, 2015.

[11] H. H. Zeineldin , Yasser Abdel-Rady I. Mohamed, Vinod Khadkikar, and V. Ravikumar Pandi, "A Protection Coordination Index for Evaluating Distributed Generation Impacts on protection for Meshed Distribution Systems," IEEE Transactions on Smart Grid, vol. 4, pp. 1523-1532, 2013.

[12] Prashant P. Bedekar, Sudhir R. Bhide, Vijay S. Kale., "Optimum coordination of overcurrent relays in distribution system using dual simplex method," in Proceedings of $2^{\text {nd }}$ International Conference on Emerging Trends in Engineering and Technology (ICETET), Nagpur, 2009.

[13] Hebatallah Mohamed Sharaf, H. H. Zeineldin, Doaa Khalil Ibrahim and Essam EL-Din Abou EL-Zahab, "Protection Coordination of Directional Overcurrent Relays Considering Fault Current Direction," in Proceedings of $5^{\text {th }}$ IEEE conference on Innovative Smart Grid Technologies, ISGT 2014, Istanbul, Turkey, 12-15 Oct 2014.

[14] A.Y. Abdelaziz, H.E.A. Talaat, A.I. Nosseir, Ammar A. Hajjar., "An adaptive protection scheme for optimal coordination of overcurrent relays," Electric Power Systems Research, vol. 61, pp. 1-9, 2002.

[15] Walid El-Khattam, Tarlochan S. Sidhu, "Resolving the impact of distributed renewable generation on directional overcurrent relay coordination: a case study," IET Renewable Power Generation, vol. 3, pp. 415-425, 2008.

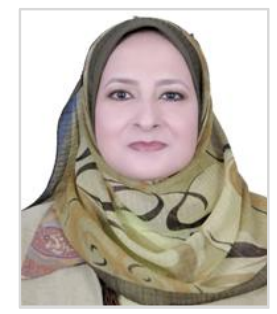

Doaa Khalil Ibrahim She was born in Egypt in December 1973. She received the M.Sc. and Ph.D. degrees in digital protection from Cairo University, Cairo, Egypt, in 2001 and 2005, respectively. From 1996 to 2005, she was a Demonstrator and Research Assistant with Cairo University. In 2005, she became an Assistant Professor with Cairo University. In 2011, she became an Associate Professor with Cairo University. From 2005 to 2008, she contributed to a World Bank Pr oject in Higher Education Development in Egypt. Since 2009, she has contributed to the Program of Continuous Improvement and Qualifying for Accreditation in Higher Education in Egypt. Her research interests include digital protection of power system as well as utilization and generation of electric power, distributed generation and renewable energy sources.

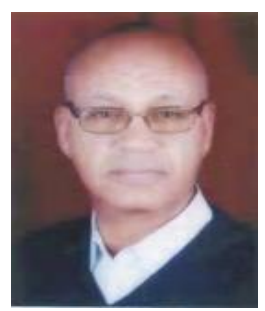

Essam EL-Din Abou EL-Zahab $\mathrm{He}$ received the BSc. and MSc. degrees in electrical power and machines from Cairo University, Giza, Egypt, in 1970 and 1974, respectively. He received the $\mathrm{PhD}$. degree in Electrical Power from Paul Sabatier, Toulouse France, in 1979. Currently he is a Professor in the department of electrical power and machines at Cairo University. He was an instructor in the department of electrical power and machines at Cairo University from 1970 to 1974 . His research areas include protection system, renewable energy, and power distribution. He is also the author or co-author of many referenced journal and conference papers.

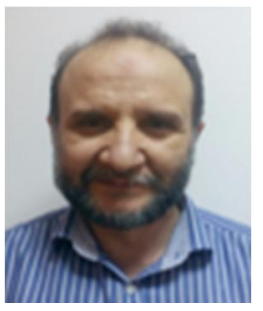

Saadoun Abd El Aziz Mostafa He was graduated from Cairo University, Faculty of Engineering, Electrical Power and Machines Department, Egypt, in 1992, and received the M.Sc. from Cairo University at 2006. From 1993 till now, he was an executive engineer and technical manager in Arab Contractor Company, Egypt. He is currently pursuing the Ph.D. degree in power engineering. 